\title{
OBITUARY
}

\section{No chromosome arm unturned: in memory of Roland Berger} 1934-2012

Leukemia (2014) 28, 464-469; doi:10.1038/leu.2013.340

One year ago on 1 October 2012, Dr Roland Berger, one of the most respected pioneers in the field of cytogenetics, died at the age of 78 years (Figure 1). A number of colleagues and friends, many of whom had known Roland since the 1950s, endorse that he was a unique scientist in his ability to combine remarkable intelligence and insight with French skepticism. Their contributions are collected into this article reflecting their memories and admiration of his scientific career.

\section{EARLY YEARS IN CYTOGENETICS}

In the late 1950s, Marthe Gautier, a pediatrician, established the first laboratory in France for the study of genetics at the pediatric Trousseau Hospital on the eastern edges of Paris, as part of the service of Raymond Turpin. She was central to the successful development of tissue culture techniques used at that time. However, Marthe chose not to pursue her career in genetics and was succeeded as head of the laboratory by Jerome Lejeune. In 1962, when Roland had just completed his 4-year internship as a pediatrician in Turpin's department, he wished to transfer to a career in research. He was tempted by the new discipline and technology of cytogenetics, which offered a vast and diverse field of research. Lejeune's laboratory was ideally situated for this venture both in time, with the recent discovery of the trisomy 21 in Down syndrome, and in place, in that he was able to transfer seamlessly from one career to the other in the same location. Roland successfully convinced Lejeune to employ him and gratefully abandoned the formalities of the medical profession to develop his new career in research, under the watchful eye of the pediatric medical team. With Marthe among them, they used to visit the laboratory on a regular basis. They could be heard from afar, approaching down the corridor with the precise tap of their

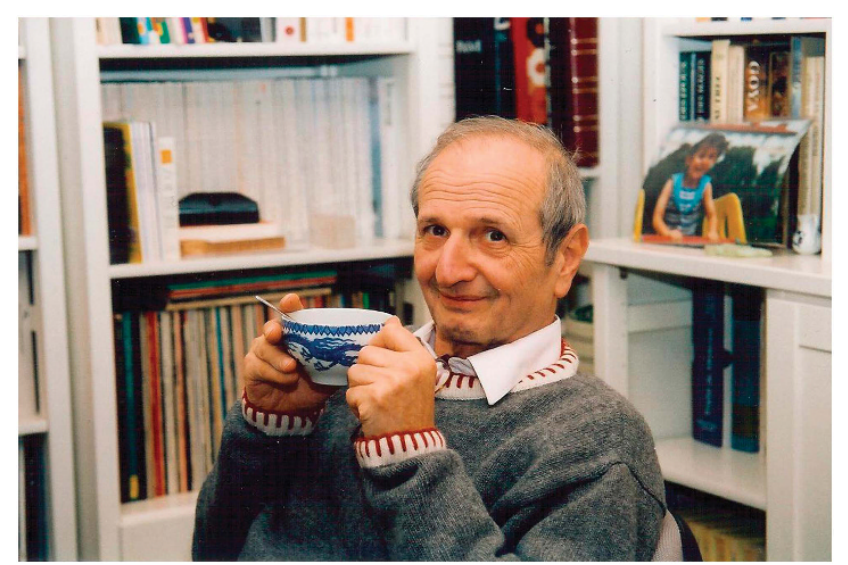

Figure 1. A rare photograph of Dr Roland Berger taken in 1995. well-polished black shoes, each of them in a dark navy full-length cloak. Their arrival gave the air that Napoleon and his generals had arrived; however, when they sank to rest on the laboratory chairs and lit up their Gauloises it was a different story.

Roland's initial studies were aimed at understanding the mechanisms behind constitutional chromosomal abnormalities in children. At that time, cytogenetic analysis was carried out on fibroblast cultures from skin biopsies, which, although lengthy to preform, was highly successful. Roland learnt how to take and culture skin cells among other laboratory techniques, including preparation of karyograms from photographs with scissors and glue. Everything seemed possible in cytogenetics in those early days: Lejeune hoped that by incubating human chromosomes with extracts from fruit fly salivary glands they would produce polytene chromosomes; one of his less successful ideas. Diagnosis of new congenital malformations was the laboratory's daily fare, such as the excitement when Lejeune's cry went up 'Come and see this child who cries like a cat!'. ${ }^{1}$ One of Roland's first publications was written in a French journal in 1963, co-authored by Lejeune and titled 'On a case of 17 trisomy'.'

Roland presented his doctoral thesis in 1968 entitled 'Méthodologie de l'Analyse des Chromosomes des Tumeurs'. As it was a thesis in the Faculty of Sciences, Paris, he needed an additional certificate in 'Physiologie Cellulaire' in order to qualify. After work he would dash through Paris in his 'Deux Chevaux' in order to arrive on time for the lectures. Roland expanded his knowledge by presenting his cases at scientific conferences, notably the International Congress of Genetics, The Hague, The Netherlands, 1963, where he first met Herman Van den Berghe, and the International Genetic Congress, Paris, 1970, with its explosion of different chromosomal-banding techniques, which followed the fluorescence method using Quinacrine.

Subsequently, Roland left Lejeune's laboratory and founded one of his own. He arrived in Hôpital Saint Louis, the large French hematological center, in the 1970s. At that time, bone marrow transplantation of Fanconi's anemia was hopeless: the children suffered enormous toxicity. The cytogenetics team demonstrated a high level of chromosome breakage in cells from Fanconi's anemia patients treated with cyclophosphamide metabolites; drugs used in the transplant-conditioning procedure. ${ }^{3}$ As a result of these findings, Elaine Gluckman subsequently drastically reduced the use of this drug in Fanconi's anemia patients, paving the way to the first successful cellular therapy for a genetic disease. Reflecting his continuing interest in Fanconi's anemia, Roland published 'Chromosomal studies of leukemic and preleukemic Fanconi's anemia patients': examples of acquired 'chromosomal amplification' with his loyal, long standing and devoted technician, Maryvonne Busson-Le Coniat. ${ }^{4}$

In Roland's early years as a cytogeneticist, he also published a wide range of cytogenetic topics including the following: constitutional abnormalities, gene localization and chromosome mapping. Not deterred by their high failure rate and difficulties of chromosomal analysis, he developed an interest in malignancy and transferred to the study of hematological samples. He was interested in the effect of constitutional chromosomal abnormalities in leukemia. ${ }^{5}$ His first original experimental paper on leukemia concerned a Down's syndrome baby with congenital leukemia who 
had acquired a leukemic clone with 54 chromosomes and subclones with duplications of each of the chromosomes involved in the main clone. $^{6}$ He had entered the realms of understanding the way in which cancer progressed and introduced the term 'clonal evolution'. In fact, in the book 'Human Chromosome', published 2 years later, it was concluded that 'chromosomal abnormalities were the neoplastic process itself'. In the early 1980s, he produced several papers with leukemia or cancer as their principal theme, including acute myeloid leukemia (AML), acute lymphoblastic leukemia (ALL), lymphoma and solid tumors. ${ }^{78}$ We surely now, more than 50 years later, have the answers to the fundamental question he asked: are chromosomal abnormalities the cause or the consequence of cancer? In those days, with no bands on chromosomes, making the recognition of abnormal chromosomes almost impossible, he nevertheless developed a 'global graphic technique' or 'profile method' for comparing the karyotypes within and between over 40 malignant solid and liquid tumor effusions after direct or short-term culture.

\section{INTERNATIONAL WORKSHOPS ON CHROMOSOMES IN LEUKEMIA}

Roland was an important participant in the International Workshops on Chromosomes in Leukemia of which there were six held over a period of more than 10 years. The reports resulting from these Workshops are listed in Table 1. They were an outgrowth of workshops on histocompatibility antigens organized by Rose Paine and others, including Walter and Julia Bodmer, Oxford. After the revolutionary cytogenetic findings achieved using chromosome banding, it was crucial to investigate how reproducible they were and what valid clinical and pathological correlations could be made. In general, no cytogenetics laboratory had more than 10-20 cases with any particular chromosomal abnormality; therefore, collaborations between laboratories and pooling of their data were critical if progress was to be made.

The First Workshop was held in Helsinki in 1977, in connection with the International Chromosome Conference organized by Albert de la Chapelle. There were 16 participants, three from the United States of America and the remainder from six European countries. They provided data on 223 patients with chronic myeloid leukemia and 241 patients with AML. One aim of the Workshop was to characterize chromosomal abnormalities in $\mathrm{AML}$; only two translocations, $t(8 ; 21)(q 22 ; q 22)$ and $t(15 ; 17)(q 21 ; q 11)$, were identified. Among 17 patients with acute promyelocytic leukemia (APL), only nine had $t(15 ; 17)$ and six were thought to be normal. The Second Workshop was held in Leuven in 1979, hosted by Herman Van den Berghe, to which Roland was invited to participate. From the submitted data, the same division was noted; among 80 APL patients, 33 had the translocation and 40 had a normal karyotype. It was observed that the incidence of the translocation increased after several days of bone marrow cell culture. Thus, the close association of morphology and translocations was confirmed- $t(8 ; 21)$ and $t(15 ; 17)$ related to particular subtypes of $A M L$ - namely $A M L M 2$ and $A M L M 3$ (and AML M3 variants), respectively.

The Third Workshop in 1980 saw a change in several ways. It was organized and financed by Felix Mitelman and his colleagues in Lund. The subject was ALL and clinicians were invited for the first time. With 330 cases, about $50 \%$ children, one could not only compare the incidence of various abnormalities in children versus adults but also compare survival among the different abnormalities. It also became apparent that the high hyperdiploid group, greater than 50 chromosomes, was different from the hyperdiploid (47-49 chromosomes), both cytogenetically and clinically. It became evident that patients with karyotypes with a modal number $>50$ chromosomes had the best response to treatment, as reported earlier by Lorna Secker-Walker, ${ }^{19}$ whereas those with $\mathrm{t}(4 ; 11)<46$ chromosomes or Philadelphia chromosome had the worst outcome. For the first time, it was shown that karyotype was
Table 1. Reports from the Six International Workshops on Chromosomes in Leukemia

1. First International Workshop on Chromosomes in Leukemia. Chromosomes in acute non-lymphocytic leukaemia. $\mathrm{Br} J$ Haematol 1978; 39: 311-316.

2. First International Workshop on Chromosomes in Leukaemia. Chromosomes in Ph1-positive chronic granulocytic leukaemia. Br J Haemato 1978; 39: 305-309.

3. General report on the First International Workshop on Chromosomes in Leukemia. Int J Cancer 1978; 21: 307-308.

4. Second international workshop on chromosomes in leukemia. Leuven, Belgium, October 2-6, 1979. Cancer Genet Cytogenet 1980; 2: 89-113.

5. Second International Workshop on Chromosomes in Leukemia. Cancer Res 1980; 40: 4826-7.

6. Third International Workshop on Chromosomes in Leukemia (1980): Chromosomal abnormalities in acute lymphoblastic leukemia: structural and numerical changes in 234 cases. Cancer Genet Cytogenet 1981; 4: 101-110.

7. Third International Workshop on Chromosomes in Leukemia (1980): Chromosome abnormalities and their clinical significance in acute lymphoblastic leukemia. Cancer Res 1983; 43: 868-873.

8. Fourth International Workshop on Chromosomes in Leukemia (1982): Constitutional chromosome abnormalities in patients with acute nonlymphocytic leukemia. Cancer Genet Cytogenet 1984; 11: 282-283.

9. Fourth International Workshop on Chromosomes in Leukemia: a prospective study of acute nonlymphocytic leukemia. Karyotypic patterns in multiple clones. Cancer Genet Cytogenet 1984; 11: 322-325.

10. Fourth International Workshop on Chromosomes in Leukemia: Clinical significance of chromosomal abnormalities in acute nonlymphoblastic leukemia. Cancer Genet Cytogenet 1984; 11: 332-350.

11. Fourth International Workshop on Chromosomes in Leukemia, 1982: Abnormalities of chromosome 17. Cancer Genet Cytogenet 1984; 11: 314-315.

12. Fourth International Workshop on Chromosomes in Leukemia (1982): Chromosomes in acute promyelocytic leukemia. Cancer Genet Cytogenet 1984; 11: 288-293.

13. Fourth International Workshop on Chromosomes in Leukemia 1982: Correlation of karyotype and occupational exposure to potential mutagenic/carcinogenic agents in acute nonlymphocytic leukemia. Cancer Genet Cytogenet 1984; 11: 326-331.

14. Fourth International Workshop on Chromosomes in Leukemia 1982: Secondary leukemias associated with neoplasia: treated and untreated. Cancer Genet Cytogenet 1984; 11: 319-321.

15. Fifth International Workshop on Chromosomes in L-L. Correlation of chromosome abnormalities with histologic and immunologic characteristics in non-Hodgkin's lymphoma and adult T cell leukemia-lymphoma. Blood 1987; 70: 1554-1564.

16. Sixth International Workshop on chromosome in Leukemia. Cancer Genet Cytogenet 1989; 40: 141-230.

an essential and, in fact at that time, the most important independent predictor of survival. These associations are used for risk stratification of ALL patients for treatment to this day.

The Fourth Workshop in 1982, organized by Janet Rowley in Chicago, was the first one where data were collected prospectively. The planning for this Workshop began at the Second 
Workshop in 1979. It focussed on AML and included every patient with a successful cytogenetic result. It had the largest number of participants ${ }^{31}$ and included the original member cytogeneticists as well as invitées from South Africa, Australia and Japan, who contributed 660 de novo and 56 treatment-related AML. In addition to $t(8 ; 21)$ and $A P L, 30$ patients had abnormalities of the long arm of chromosome 11 (11q) and a new group was observed, tentatively called inversion. ${ }^{16}$ Patients with treatment-related AML had complex karyotypes with abnormalities of chromosomes 5 and 7 . The preponderance of translocations in younger patients less than 15 and up to 30 years, and of chromosome 5 and 7 abnormalities, as well as complex karyotypes in older individuals, was striking. Moreover, karyotype was the most important independent prognostic factor for survival.

The Fifth Workshop was held in Japan in 1984. One of the most striking findings was the difference in frequency of various clinical/pathological subtypes according to geography. Among 57 cases of follicular lymphoma with $t(14 ; 18)$, only one came from Japan! The last Workshop in 1987 was held in London. Its focus was the integration of cytogenetics with molecular genetics, especially cloned translocation breakpoints. This Workshop also examined long-term ( $>5$ year) survival of the 66 AML patients who remained alive from the Fourth Workshop and whose clinical data were available for analysis at the Sixth Workshop. The predictors of long survival were younger age at diagnosis and translocations, $\mathrm{t}(8 ; 21)$ and $\mathrm{t}(15 ; 17)$, as well as inversion, ${ }^{16}$ with 10 $30 \%$ alive at 10 years compared with those with chromosome 5 and 7 abnormalities, with no survivors after 6.5 years. Roland Berger was a major contributor of patient data but also brought scientific rigor to these meetings.

\section{BANDING (AND DNA) YEARS}

With Georges Flandrin's team, Roland focused on the study of AML. Among their multiple findings, they showed that in APL, erythroblasts with good-quality metaphases and a normal karyotype masked the poor quality leukemic metaphases with $t(15 ; 17)$. This observation explained the frequent karyotype discrepancy that consequently was efficiently overcome by a simple 2-day culture, as noted in the Second International Workshop. This observation was instrumental in defining the specificity of $t(15 ; 17)$ and its biological meaning, leading to the first model of targeted therapy in APL with retinoids.

The biological signification of translocations was the central question in those years. During his work on Burkitt's lymphoma, Roland's group was the first to locate the translocation breakpoints of the immunoglobulin heavy and light chains, thereby implicating the location of an oncogene, later identified as MYC, on $8 q 24$, to be dysregulated by a position effect. ${ }^{8-10}$ From this finding, the convergence of cytogenetics and molecular biology began, leading to the discovery of large numbers of significant genetic alterations associated with translocations in malignancies. Roland was mindful of the importance of human gene mapping and he became the chair of the first committee on 'Chromosome rearrangements in acquired malignant diseases' established in 1981 in Human Gene Mapping 6 conference in Oslo. In his own laboratory, he pioneered molecular cytogenetics by introducing chromosome sorting, chromosome microdissection, in situ hybridization with banding and early fluorescence in situ hybridization of unique sequences.

Roland had a keen interest in abnormalities of $11 \mathrm{q}$, which culminated in the publication of a review with Olivier Bernard highlighting the 'Molecular Basis of 11q23 Rearrangements in Hematopoietic Malignant Proliferations'. ${ }^{20}$ He was an active participant in the 'European Union Concerted Action Workshop on 11q23', organized by Lorna Secker-Walker in London in 1997. ${ }^{21,22}$ This Workshop defined the individual $11 q 23$ partners
Table 2. Articles from Groupe Français de Cytogénétique Hématologique

1. Chromosome analysis of 63 cases of secondary nonlymphoid blood disorder: A cooperative study. Cancer Genet Cytogenet 1984; 12: 95-104.

2. Unusual $\mathrm{Ph}$ translocations in the French prospective study on chronic myeloid leukemia. Cancer Genet Cytogenet 1985; 16: 305-9.

3. Cytogenetics of chronic myelomonocytic leukemia. Cancer Genet Cytogenet 1986; 21: 11-30.

4. Cytogenetics of acutely transformed chronic myeloproliferative syndromes without a Philadelphia chromosome. A multicenter study Of 55 patients. Cancer Genet Cytogenet 1988; 32: 157-68.

5. Findings in leukemic cells of 56 patients with constitutional chromosome abnormalities. A cooperative study. Cancer Genet Cytogenet 1988; 35: 243-52.

6. Acute myelogenous leukemia with a 8;21 translocation. A report on 148 cases. Cancer Genet Cytogenet 1990; 44: 169-79.

7. Philadelphia-negative (Ph-) chronic myeloid leukemia (CML): comparison with $\mathrm{Ph}+\mathrm{CML}$ and chronic myelomonicytic leukemia. Blood 1991; 78: 205-11.

8. Isochromosome $21 \mathrm{q}$ in hematologic malignancies. Cancer Genet Cytogenet 1991; 55: 101-5.

9. Chronic myelomonocytic leukemia: single entity or heterogeneous disorder? A prospective multicenter study of 100 patients. Cancer Genet Cytogenet 1991; 55: 57-65.

10. $t(10 ; 11)(p 13-14 ; q 14-21)$ : a new recurrent translocation on T-cell acute lymphoblastic leukemias. Genes Chromosomes Cancer 1991; 3: 411-5.

11. Collaborative study of karyotypes in childhood acute lymphoblastic leukemias. Leukemia 1993; 7: 10-9.

12. Acute leukemia treated with intensive chemotherapy in patients with a history of previous chemo-and/or radiotherapy: prognostic significance of karyotype and preceding myelodysplastic syndrome. Leukemia 1994; 8: 87-91.

13. Cytogenetic analysis in patients with primary myelodysplastic syndromes in leukemic transformation. A report on 94 cases. Hematol Cell Therapy 1996; 38: 177-81

14. Cytogenetic abnormalities in adult acute lymphoblastic leukemia: correlations with hematologic findings and outcome. Blood 1996; 87: 3135-42.

15. Forty-four cases of childhood myelodysplasia with cytogenetics. Leukemia 1997; 11: 1478-85.

16. with Groupe Français d'Hématologie Cellulaire, UK Cancer Cytogenetics Group, and BIOMED 1 European CommunityConcerted Action Molecular Cytogenetic Diagnosis in Haematological Malignancies. Characterization of acute promyelocytic leukemia cases lacking the classic $t(15 ; 17)$ : results of the European Working Party. Blood 2000; 9: 1297-308.

17. with Groupe Français d'Hématologie Cellulaire; UK Cancer Cytogenetics Group; BIOMED 1 European CommunityConcerted Action "Molecular Cytogenetic Diagnosis in Haematological Malignancies". A new morphologic classification system for acute promyelocytic leukemia distinguishes cases with underlying PLZF/RARA gene rearrangements. Blood 2000; 96: 1287-96.

18. with Intergroupe Francophone du Myélome. Cytogenetic interphase and multicolor fluorescence in situ hybridization analyses in primary plasma cell leukemia: a study of 40 patients at diagnosis. Blood 2001; 97: 822-5.

19. Hypodiploidy is a major prognostic factor in multiple myeloma. Blood 2001; 98: 2229-38. 
Table 2. (Continued)

$20 \mathrm{CD} 4(+), \mathrm{CD} 56(+) \mathrm{CD} 2$ acute leukemia is characterized by recurrent clonal changes affecting six major targets: a study of 21 cases. Blood 2002; 99: 4154-9.

21. with Groupe Français d'Hématologie Cellulaire. Cytogenetic profile of childhood and adult megakaryoblastic leukemia (M7). Blood 2002; 100: 618-26.

22. Common trisomies in M7. Blood 2002; 100: 3838-9.

23. with Groupe Français d'Hématologie Cellulaire. Acute megakaryoblastic leukaemia: a national clinical and biological study of 53 adult and childhood cases. Leuk Lymphoma 2003; 44: 49-58.

24. $\mathrm{t}(5 ; 14) / \mathrm{HOX} 11 \mathrm{~L} 2$-positive T-cell acute lymphoblastic leukemia. Leukemia 2003; 17: 1851-7.

25. with Groupe Français d'Hématologie Cellulaire. MO AML, clinical and biologic features of the disease, including AML1 gene mutations; a report of 59 cases. Blood 2003; 101: 1277-83.

26. Introduction aux recommandations pour la prise en charge cytogénétique des hémopathies. Pathol Biol 2004; 53: 235-7.

27. Recommandations pour la prise en charge cytogénétique de la leucémie myéloïde chronique (LMC). Pathol Biol 2004; 53: 238-240.

28. Recommandations pour la prise en charge cytogénétique des syndromes myéloprolifératifs autres que la leucémie myéloïde chronique. Pathol Biol 2004; 53: 241-4.

29. Recommandations pour la prise en charge cytogénétique de syndromes myélodysplasiques. Pathol Biol 2004; 53: 245-7.

30. Recommandations pour la prise en charge cytogénétique des leucémies aiguës myéloïdes. Pathol Biol 2004; 53: 248-50.

31. Recommandations pour la prise en charge cytogénétique des leucémies aiguës lymphoblastiques de l'adulte et de l'enfant. Pathol Biol 2004; 53: 251-3.

32. Recommandations pour la prise en charge cytogénétique d'une leucémie lymphoïde chronique. Pathol Biol 2004; 53: 254-6.

33. Recommandations pour la prise en charge cytogénétique des lymphomes malins non Hodgkiniens de I'nfant ( $<18$ ans) au diagnostic. Pathol Biol 2004; 53: 257-9.

34. Recommandations pour la prise en charge cytogénétique des lymphomes malins non hodgkiniens de l'adulte. Pathol Biol 2004; 53: 260-2.

35. Recommandations pour la prise en charge cytogénétique des myélomes multiples. Pathol Biol 2004; 53: 263-4.

36. with Groupe Français d'Hématologie Cellulaire. Cytogenetic study of 75 erythroleukemias. Cancer Genet Cytogenet 2005; 163: $113-22$.

37. Loss of the NPM1 gene in myeloid disorders with chromosome 5 rearrangements. Leukemia 2006; 20: 319-21.

38. Overexpression of CEBPA resulting from the translocation $t(14 ; 19)(q 32 ; q 13)$ of human precursor $B$ acute lymphoblastic leukemia. Blood. 2006; 108: 3560-3.

39. Abnormalities of the long arm of chromosome 21 in 107 patients with hematopoietic disorders. Cancer Genet Cytogenet 2006; 166: 1-11.

40. NUP98 rearrangements in hematopoietic malignancies. Leukemia 2006; 20: 696-706.

41. Fluorescence in situ hybridization analysis of 110 hematopoietic disorders with chromosome 5 abnormalities: do de novo and therapy-related myelodysplastic syndromeacute myeloid leukemia actually differ? Cancer Genet Cytogenet 2007; 176: 1-21.
Table 2. (Continued)

42. Clinical, cytogenetic and molecular characteristics of 14 T-ALL patients carrying the TCRbeta-HOXA rearrangement. Leukemia. 2007; 21: 121-8.

43. Hyperdiploid karyotypes in acute myeloid leukemia define a novel entity: a study of 38 patients. Leukemia 2008; 22: 132-7

44. EVI1 overexpression in $\mathrm{t}(3 ; 17)$ positive myeloid malignancies results from juxtaposition of EVI1 to the MSI2 locus at 17q22. Haematologica 2008; 93: 1903-7.

45. The most frequent $\mathrm{t}(14 ; 19)(\mathrm{q} 32 ; \mathrm{q} 13)$-positive B-cell malignancy corresponds to an aggressive subgroup of atypical chronic lymphocytic leukemia. Leukemia 2008; 22 2123-7.

46. Acute myeloid leukemia with 8p11 (MYST3) rearrangement: an integrated cytologic, cytogenetic and molecular study. Leukemia 2008; 22: 1567-75.

47. with Belgian Cytogenetic Group for Hematology and Oncology. Heterogeneous patterns of amplification of the NUP214-ABL1 fusion gene in T-cell acute lymphoblastic leukemia. Leukemia 2009; 23: 125-133

48. Genome profiling of acute myelomonocytic leukemia: alteration of the MYB locus in MYST3-linked cases. Leukemia 2009; 23: 85-94.

49. Analyses of TET2 mutations in post-myeloproliferative neoplasm acute myeloid leukemias. Leukemia 2010; 24: 201-3.

50. Chromosomal abnormalities in transformed Ph-negative myeloproliferative neoplasms are associated to the transformation subtype and independent of JAK2 and the TET2 mutations. Genes Chromosomes Cancer 2010; 49: 919-27.

51. Wide diversity of PAX5 alterations in B-ALL. Blood 2010; 115: 3089-97.

52. with Belgian Cytogenetic Group for Hematology and Oncology. Refinement of 1 p36 Alterations Not Involving PRDM16 in Myeloid and Lymphoid Malignancies. PLoS One 2011; 6: e26311.

53. Specific chromosomal IG translocations have different prognoses in chronic lymphocytic leukemia. Am J Blood Res 2011; 1: 13-21

54. with Belgian Cytogenetic Group for Haematology and Oncology. PRDM16 (1p36) translocations define a distinct entity of myeloid malignancies with poor prognosis but may also occur in lymphoid malignancies. Br J Haematol 2012; 156: 76-88.

55. Chronic lymphocytic leukemia and prolymphocytic leukemia with MYC translocations: a subgroup with an aggressive disease course. Ann Hematol 2012; 91: 863-73.

56. Patterns of genomic aberrations suggest that Burkitt lymphomas with complex karyotype are distinct from other aggressive B-cell lymphomas with MYC rearrangement. Genes

both cytogenetically and clinically; these papers continue to be referred to today.

One highly significant finding was Roland's discovery of the cryptic translocation, $\mathrm{t}(12 ; 21)(\mathrm{p} 13 ; \mathrm{q} 22)$, with his then PhD student, Serge Romana. ${ }^{23-25}$ This late discovery in 1994 was made by the application of chromosome paints to metaphases from patients with abnormalities of chromosome 12 . The molecular nature of the translocation arising from a fusion between the TEL and AML1 genes was made simultaneously by Roland's group and Todd Golub in United States of America in $1995,{ }^{26}$ as well as the strong association of this translocation with deletions of the short arm of 
the chromosome 12 not involved in the translocation. The TELAML1 fusion (now known as ETV6-RUNX1) occurs in $\sim 25 \%$ childhood B-lineage ALL. It is associated with a young age and an excellent outcome, thus remaining important for risk stratification for treatment.

In the discovery of novel chromosomal abnormalities, Roland's group was one of the first to identify that often in ALL, marker chromosomes in the absence of one copy of chromosome 21 were duplicated chromosome 21 with multiple copies of the AML1 gene. ${ }^{27,28}$ This intriguing abnormality now defines a novel cytogenetic subgroup, named intrachromosomal amplification of chromosome 21 (iAMP21), with a poor outcome on standard therapy. ${ }^{29-33}$ Intensified treatment has been shown to significantly improve outcome, which has become standard practice on clinical trials. $^{34,35}$ From these few examples, it is evident that his cytogenetic discoveries in human leukemia led to improved precision in classification of leukemic subtypes combined with a deeper understanding of their prognostic significance.

\section{PROFESSIONAL DUTIES}

Roland was an ethical man with a sound perception of 'public service'. He was known as an 'activist' because, through his enthusiasm for the importance of acquired cytogenetic abnormalities, he persuaded the 'Securité Sociale' (the French National Health Service) that cytogenetic testing should be included in the list of diagnostic procedures that were reimbursed, by pleading that they were essential to the optimum care of patients who suffered from hematological diseases. Thanks to his efforts at the French Ministry of Health, the external quality assessment for the field of acquired cytogenetics was initiated.

Roland strongly considered teaching and mentoring of his students as an essential part of his professional duty. He trained a number of pupils who continue in cytogenetics or research activity in French public institutions. He mentored Philippe Jonveaux, Serge Romana, Florence Nguyen-Khac towards University qualifications and Alain Bernheim and Olivier Bernard in research careers. He inspired many cytogeneticists and researchers at some point in their lives, for which the list is too long to be included.

Table 3. Quotations of fond memories from friends and colleagues of Dr Roland Berger

Despite his questioning: "Yes, but---" and his "prove it to me" attitude, he was a warm and loyal friend who will be greatly missed.

Invitations to his laboratory resulted in two hours and more being enthralled and fascinated by Roland's enthusiastic descriptions of his latest findings.

Roland was always extremely reserved, almost shy, reflected by the observation that in a group photo you had to look on the last row to find him

He was a very pleasant boy. His work has been of great worth and I admire the courage he displayed to execute his ideas.

I shall remember Roland for his fine mind and total dedication to his work, for his honesty, for his unfailing kindness and for his modesty. When asked what he thought about the importance of his discoveries his response was: 'Ce n'etaient que de petites choses - they were only little things'.

I loved his company, his caustic humor and excellent insights. In his last mail a few months ago he apologized for not being able to come to visit, but, he said, "my heart is there".

I have lost a very, very dear friend.

\section{GROUPE FRANCOPHONE DE CYTOGÉNÉTIQUE HÉMATOLOGIQUE}

Roland succeeded in maintaining cytogenetics as an active domain in France. Together with Joseph Tanzer in 1978, Roland was one of the founders and leading scientists of the Groupe Français (later changed to Francophone) de Cytogénétique Hématologique (GFCH). This group performed excellent collaborative studies and produced a series of authoritative papers, which characterized novel and established cytogenetic subgroups. Roland was immersed in GFCH studies, both for the subject, the studies themselves, and article writing, which was eloquently undertaken. He led the group until his retirement in 2008 . The GFCH meant a lot to him, and he followed with interest their ongoing work, long after his retirement. It was important that this group continued after him; hence, two of his pupils took his place: Serge Romana (2008-2012) and Florence Nguyen-Khac (from 2012). At this time, 56 original articles have been published on behalf of the GFCH, which are listed in Table 2. His enormous commitment to GFCH was equal to every cause that he deemed worthy of fighting for. He is fondly remembered by his friends and colleagues with quotations listed in Table 3.

CJ Harrison ${ }^{1}$, JD Rowley ${ }^{2}, \mathrm{H}$ Van den Berghe ${ }^{3}$, A Bernheim $^{4}$, M Martineau ${ }^{5}$, M Gautier ${ }^{6}$, M Le Coniat-Busson ${ }^{7}$, S Romana ${ }^{8}$

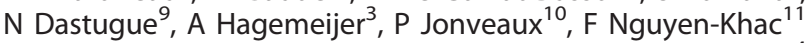
and OA Bernard ${ }^{4}$

'Leukaemia Research Cytogenetics Group, Northern Institute for Cancer Research, Newcastle University, Newcastle University, Level 5, Sir James Spence Institute, Royal Victoria Infirmary, Newcastle-upon-Tyne, UK;

${ }^{2}$ Section of Hematology/Oncology, The University of Chicago Medicine \& Biological Sciences, Knapp, Chicago, IL, USA;

${ }^{3}$ VIB Center for the Biology of Disease, KU Leuven Center for Human Genetics, Leuven, Belgium;

${ }^{4}$ U985 INSERM, Villejuif, France;

${ }^{5}$ Leukemia Research Cytogenetics Group, Cancer Sciences Division, University of Southampton, Southampton, UK;

${ }^{6}$ Department of Genetics, Trousseau Hospital, Paris, France; ${ }^{7}$ E0210 INSERM, Tour Pasteur, Hôpital Necker, Paris, France; ${ }^{8}$ Service d'histologie, embryologie et cytogénétique, Hôpital Necker-Enfants Malades, Paris, France

${ }^{9}$ Laboratoire d'hématologie, Génétique des Hémopathies, Hôpital PURPAN, Toulouse, France;

${ }^{10}$ Laboratoire de Génétique Médicale, Centre Hospitalier Universitaire de Nancy, Vandoeuvre-les-Nancy, France and

${ }^{11}$ Unité de Cytogénétique Hématologique, Service d'Hématologie Biologique, GH Pitié-Salpêtrière, Paris, France E-mail: christine.harrison@newcastle.ac.uk

\section{REFERENCES}

1 Lejeune J, Lafourcade J, Berger R, Vialatte J, Boeswillwald M, Seringe P et al. [ 3 Cases of partial deletion of the short arm of a 5 chromosome]. Comptes rendus hebdomadaires des seances de l'Academie des sciences 1963; 257: 3098-3102.

2 Lejeune J, Delthil P, Berger R. [On a case of 17 trisomy]. Archives francaises de pediatrie 1963; 20: 737-740.

3 Berger R, Bernheim A, Gluckman E, Gisselbrecht C. In vitro effect of cyclophosphamide metabolites on chromosomes of Fanconi anaemia patients. Br J Haematol 1980; 45: 565-568.

4 Berger R, Bernheim A, Le Coniat M, Vecchione D, Schaison G. Chromosomal studies of leukemic and preleukemic Fanconii's anemia patients: examples of acquired 'chromosomal amplification.' Hum Genet 1980; 56: 59-62.

5 Berger R. [Constitutional chromosome abnormalities and leukemia]. Nouvelle revue francaise d'hematologie 1970; 10: 99-107.

6 Berger R, Weisgerber C, Bernard J. [Clonal evolution during acute leukemia in a Mongol child (author's transl)]. Nouvelle revue francaise d'hematologie 1973; 13: 229-236. 
7 Berger R, Bernheim A, Daniel MT, Valensi F, Flandrin G. [Translocation t $(8 ; 21)$ and acute granulocytic leukemia: interpretation of normal mitoses]. CRSeancesAcadScilll 1981; 292: 289-291.

8 Berger R, Bernheim A, Flandrin G, Daniel MT, Schaison G, Brouet JC et al. [Translocation $\mathrm{t}(8 ; 14)$ in acute lymphoblastic leukaemia, Burkitt type (author's transl)]. NouvPresse Med 1979; 8: 181-183.

9 Berger R, Bernheim A, Brouet JC, Daniel MT, Flandrin G. t(8;14) translocation in a Burkitt's type of lymphoblastic leukaemia (L3). Br J Haematol 1979; 43: 87-90.

10 Berger R, Bernheim A, Weh HJ, Flandrin G, Daniel MT, Brouet JC et al. A new translocation in Burkitt's tumor cells. Hum Genet 1979; 53: 111-112.

11 Berger R, Bernheim A, Flandrin G. [Absence of chromosomes abnormalities and acute leukemia: relationships with normal bone marrow cells]. CRSeancesAcadSciD 1980; 290: 1557-1559.

12 Berger R, Bernheim A, Flandrin G. Hematologie: Absence d'anomalie chromosomique et leucemie aigue: relations avec les cellules medullaires normales. CRSeancesAcadSciD 1980; 290: 125.

13 Berger R, Bernheim A, Weh HJ, Daniel MT, Flandrin G. Cytogenetic studies on acute monocytic leukemia. Leuk Res 1980; 4: 119-127.

14 Berger R, Bernheim A, Daniel MT, Valensi F, Flandrin G. Karyotypes and cell phenotypes in acute leukemia following other diseases. Blood Cells 1981; 7: 293-299.

15 Berger R, Bernheim A, Daniel MT, Valensi F, Flandrin G. Karyotype and cell phenotypes in primary acute leukemias. Blood Cells 1981; 7: 287-292.

16 Berger R, Bernheim A, Daniel MT, Valensi F, Flandrin G. Leucemies "induites". Aspects cytogenetique et cytologique. Comparaison avec des leucemies primitives. NouvRevFrHematol 1981; 23: 275-284.

17 Berger R, Bernheim A, Daniel MT, Valensi F, Flandrin G. [Induced leukemias. Cytogenetical and cytological aspects. Comparison with primitive leukemias (author's transl)]. NouvRevFrHematol 1981; 23: 275-284.

18 Lenoir GM, Preud'homme JL, Bernheim A, Berger R. Correlation between immunoglobulin light chain expression and variant translocation in Burkitt's lymphoma. Nature 1982; 298: 474-476.

19 Secker-Walker LM, Lawler SD, Hardisty RM. Prognostic implications of chromosomal findings in acute lymphoblastic leukaemia at diagnosis. Br Med J 1978; 2: 1529-1530.

20 Bernard OA, Berger R. Molecular basis of 11 q23 rearrangements in hematopoietic malignant proliferations. Genes Chromosomes Cancer 1995; 13: 75-85.

21 Lillington DM, Young BD, Berger R, Martineau M, Moorman AV, Secker-Walker LM. The $t(10 ; 11)(p 12 ; q 23)$ translocation in acute leukaemia: a cytogenetic and clinical study of 20 patients. European 11q23 Workshop participants. Leukemia 1998; 12: 801-804.

22 Martineau M, Berger R, Lillington DM, Moorman AV, Secker-Walker LM. The $t(6 ; 11)(q 27 ; q 23)$ translocation in acute leukemia: a laboratory and clinical study of 30 cases. EU Concerted Action 11q23 Workshop participants. Leukemia 1998; 12: 788-791.

23 Romana SP, Le Coniat M, Berger R. t(12;21): a new recurrent translocation in acute lymphoblastic leukemia. Genes Chromosomes Cancer 1994; 9: 186-191.

24 Romana SP, Mauchauffe M, Le Coniat M, Chumakov I, Le Paslier D, Berger R et al. The $t(12 ; 21)$ of acute lymphoblastic leukemia results in a tel-AML1 gene fusion. Blood 1995; 85: 3662-3670.

25 Romana SP, Poirel H, Leconiat M, Flexor MA, Mauchauffe $M$, Jonveaux $\mathrm{P}$ et al. High frequency of $\mathrm{t}(12 ; 21)$ in childhood $B$-lineage acute lymphoblastic leukemia. Blood 1995; 86: 4263-4269.

26 Golub TR, Barker GF, Bohlander SK, Hiebert SW, Ward DC, Bray-Ward P et al. Fusion of the TEL gene on 12p13 to the AML1 gene on 21q22 in acute lymphoblastic leukemia. Proc Natl Acad Sci USA 1995; 92: 4917-4921.

27 Busson-Le Coniat M, Nguyen KF, Daniel MT, Bernard OA, Berger R. Chromosome 21 abnormalities with AML1 amplification in acute lymphoblastic leukemia. Genes Chromosomes Cancer 2001; 32: 244-249.

28 Le Coniat M, Romana SP, Berger R. Partial chromosome 21 amplification in a child with acute lymphoblastic leukemia. Genes Chromosomes Cancer 1995; 14: 204-209.

29 Harewood L, Robinson H, Harris R, Al Obaidi MJ, Jalali GR, Martineau M et al. Amplification of AML1 on a duplicated chromosome 21 in acute lymphoblastic leukemia: a study of 20 cases. Leukemia 2003; 17: 547-553.

30 Robinson HM, Broadfield ZJ, Cheung KL, Harewood L, Harris RL, Jalali GR et al. Amplification of AML1 in acute lymphoblastic leukemia is associated with a poor outcome. Leukemia 2003; 17: 2249-2250.

31 Strefford JC, Van Delft FW, Robinson HM, Worley H, Yiannikouris O, Selzer R et al. Complex genomic alterations and gene expression in acute lymphoblastic leukemia with intrachromosomal amplification of chromosome 21. Proc Natl Acad Sci USA 2006; 103: 8167-8172.
32 Moorman AV, Richards SM, Robinson HM, Strefford JC, Gibson BE, Kinsey SE et al. Prognosis of children with acute lymphoblastic leukemia (ALL) and intrachromosomal amplification of chromosome 21 (iAMP21). Blood 2007; 109: 2327-2330.

33 Rand V, Parker H, Russell LJ, Schwab C, Ensor H, Irving J et al. Genomic characterization implicates iAMP21 as a likely primary genetic event in childhood B-cell precursor acute lymphoblastic leukemia. Blood 2011; 117: 6848-6855.

34 Moorman AV, Robinson H, Schwab C, Richards SM, Hancock J, Mitchell CD et al. Risk-Directed treatment intensification significantly reduces the risk of relapse among children and adolescents with acute lymphoblastic leukemia and intrachromosomal amplification of chromosome 21: a comparison of the MRC ALL97/ 99 and UKALL2003 Trials. J Clin Oncol 2013; 31: 3389-96.

35 Heerema NA, Carroll AJ, Devidas M, Loh ML, Borowitz MJ, Gastier-Foster JM et al. Intrachromosomal amplification of chromosome 21 is associated with inferior outcomes in children With acute lymphoblastic leukemia treated in contemporary standard-risk children's oncology group studies: A Report From the Children's Oncology Group. J Clin Oncol 2013; 31: 3397-402.

\section{MEMORIES FROM THE EDITOR-IN-CHIEF}

Berger Roland, Berat Nicole we met in our young age at a dissection table in the very first months at the medical facultythe old faculty - rather grim and austere which seemed to have been created to insufflate respect and awe in us.

I was, as usual, with my closest girlfriend student back from playing the church organ at lunchtime before the so-called 'travaux pratiques'. We tried to invite Roland to join us. We were quite attracted to him because he had an interesting face and of course, besides, he looked enigmatic. We felt that he would be a good recruit for our amateur concert orchestra but he refused.

After this we lost track of each other, all digging deep into the feudal French system where teaching at the faculty does not count but the parallel education called 'internat'-a competitive exam-possessed some of us entirely.

I left for Denmark in 1968 and married there. One day a paper was received to the first journal, which I created with Sven-Aage Killmann, Leukemia Research. It was from Roland. Roland had the good taste to remain friendly with me, whereas it came near to a fit of anger with Sven-Aage and him. Sven-Aage was very interested in Roland's data, and in his Nordic mentality pushed Roland hard to extract the best from him and his research. Roland could not understand this assault but finally the paper was written and published (It was very good with two masters at work). The title was 'Cytogenetic studies on Acute Monocytic Leukemia'.

Some years passed. We met again in Hôpital St Louis, Paris-he as the Head of Department and me as the Editor-in-Chief of Leukemia. We did not see each other often but a kind of tacit understanding, sharing the difficulties of professional life, established itself.

One day, to my surprise, he sent me a brief e-mail about the day that it was, namely, about the daring and breathtaking speech of General Charles de Gaulle to call all French People to continue the fight; it was the anniversary of the 18th of June.

Sometimes Roland would drop me a word about a chromosome he was getting interested in. I was all ears as you well imagine!

Lastly, he moved to the Hôpital Necker, Paris, a stones throw from my home. There he confided that young 'Olivier' was doing very well indeed. He was a man of few words but these words counted a lot.

All my thoughts are with his wife, Dr Brigitte Berger, and I greet her warmly as well as her family.

He was a real, nice gentleman.

Nicole Killmann Editor-in-Chief Leukemia 